\title{
Strategi pengembangan agribisnis Ulat Sutera Pemakan Daun Sing- kong di Kabupaten Malang
}

\section{Agribusiness development strategy of Cassava Leaves Silkworm Eaters in Malang District}

\author{
Farah Mutiara*, Dwi Asnani NH. \\ Universitas Tribhuwana Tunggadewi \\ JL. Telaga Warna, Tlogomas, Malang 65144-Indonesia \\ Submitted : 18 August 2017, Accepted : 15 September 2017
}

\begin{abstract}
ABSTRAK: Saat ini, kebutuhan sutera dunia sekitar 2,000 ton masih belum dapat terpenuhi dikarenakan kurangnya hasil produksi sutera alam. Indonesia memiliki potensi untuk mengembangkan persuteraan alam, jumlah produksinya tidak lebih dari 500 ton per tahun. Maka dari itu, untuk memperoleh hasil produksi yang maksimal, perlu ditunjang sumber pakan yang cukup dan berkelanjutan. Daun singkong dapat digunakan sebagai pengganti pakan ulat sutera yang disebut dengan Samia cynthia ricini. Ketersediannya pun sangat melimpah dan dengan kualitas yang baik. Penelitian ini bertujuan untuk: 1) menganalisis tingkat kelayakan dari usahatani agribisnis ulat sutera pemakan daun singkong di Kabupaten Malang, 2) mendeskripsikan strategi pemasaran yang tepat berdasarkan analisis SWOT. Metode penelitian yang digunakan adalah analisis kelayakan ekonomis atau analisis biaya-pendapatan untuk menganalisis keuntungan usaha, NPV dan IRR. Hasil analisis menyatakan bahwa kegiatan budidaya ulat sutera yang terdapat di tempat penelitian adalah cukup menguntungkan, dengan nilai keuntungan sebesar 21.753.000,- per tahun; B/C ratio sebesar 1,074, nilai NPV sebesar Rp 144.287.115,- hingga tahun kelima aliran kas dan nilai IRR sebesar 2,896\%. Strategi pengembangan yang dilakukan pada budidaya ulat sutera pemakan daun singkong sebaiknya berdasarkan atas analisis SWOT terhadap faktor internal dan eksternal S-O, S-T, W-O dan W-T.
\end{abstract}

Kata kunci: ulat sutera,daun singkong, analisis kelayakan, keuntungan, NPV, IRR, analisis SWOT

\begin{abstract}
Recently, the needs of silk in the world is about 2,000 tons per year still can not be fulfilled due to lack of silkworm productivity. Indonesia has potential to develop natural silk, its amount of production is not more than 500 tons per year. Therefore, in order to obtain maximum production results, it should be supported by feed sources should be sufficiently sustainable. Cassava leaves can be used as an alternative feed on the silkworm's farming which is call Samia cynthia ricini. The availability of its feed sources is abundant and the quality is extremely good. This study aims to: 1) analyse the feasibility level of agribusiness in cassava leaves silkworm eaters in Malang district, 2) describe the best marketing strategy based on SWOT analysis. The method used in this research was economic feasibility analysis or cost-benefit analysis which used to identify benefit, NPV and IRR. The results of the research indicate that the silkworm farming is profitable, with profit at 21.753 .000 ,- annually; with $\mathrm{B} / \mathrm{C}$ ratio of 1,074, NPV value is at Rp 144.287.115,- for a up to 5 years of cash flows, and the IRR value is at $2,896 \%$. The application of development strategy in cassava leaves silkworm eaters should be based on internal and external factor in SWOT analysis, S-O, S-T, W-O and W-T.
\end{abstract}

Keywords: caterpillar silkworm, feasibility analysis, profit, NPV, IRR, SWOT analysis

\footnotetext{
*Corresponden author: fmutiara90@gmail.com
} 


\section{PENDAHULUAN}

Persuteraan alam merupakan kegiatan agroindustri yang mempunyai rangkaian yang cukup panjang sejak penanaman pohon sumber pakan ulat sutera, pembibitan ulat sutera, pengolahan kokon, pemintalan serat dan penenunan (Departemen Kehutanan RI, 1999). Ulat sutera adalah salah satu komoditas yang cukup penting dalam menyumbang perolehan devisa negara. Saat ini permintaan kokon dan benang sutera di pasaran dunia semakin meningkat sehinggga telah memberikan peluang yang sangat prospektif bagi persuteraan alam. Saat ini, daun murbei dapat digantikan keberadaannya dengan singkong sebagai pakan ulat sutera. Hal ini mengingat secara nasional Kabupaten Wonogiri merupakan penyuplai komoditas terbaik untuk sektor pertanian diantaranya ubi kayu dengan daunnya yang dapat dimanfaatkan sebagai sumber pakan ulat sutera.

Untuk memperoleh hasil yang maksimal kegiatan tersebut perlu ditunjang oleh pengadaan sarana yang cukup, teknik yang memadai dan pemasaran yang terjamin, sehingga keterlibatan pemerintah, swasta maupun petani sangat diharapkan. Produksi benang sutera alam dunia mencapai 83.393 ton pertahun yang dihasilkan oleh negara-negara produsen terbesar yaitu Cina diikuti oleh India, Jepang, Korea, dan Brazil, sementara kebutuhan dunia lebih banyak lagi yaitu sekitar 92.743 ton per tahun, sehingga masih terdapat kekurangan yang cukup besar.

Indonesia yang memiliki potensi alam untuk pengembangan persuteraan alam, lebih-lebih produksinya baru mencapai tidak lebih dari 500 ton per tahun, jauh di bawah kebutuhan dalam negeri sendiri yaitu sekitar 2.000 ton per tahun. Dari hasil studi Dedy Rustiono dan Trimurti (2015) disimpulkan bahwa penerapan iptek dalam pengembangan budidaya ulat sutera pemakan daun singkong selama bulan 4 bulan pemeliharaan, menghasilkan tingkat kelayakan ekonomis antara lain keuntungan usaha sebesar Rp 1.821.667, Benefit Cost Ratio sebesar 1,84 dan tingkat Return on Investment sebesar 9,29 $\%$.

Berdasarkan hal-hal tersebut penelitian ini menjadi sangat penting dan menarik untuk dikaji sehingga dapat diketahui sejauh mana tingkat kelayakan dari usahatani agribisnis ulat sutera pemakan daun singkong di Kabupaten Malang.

\section{MATERI DAN METODE}

\section{Metode penentuan lokasi}

Penelitian dilakukan di Kecamatan Dau, Kecamatan Karangploso, dan Kecamatan Singosari. Penelitian ini dilakukan pada bulan Juni 2016 hingga bulan Juni 2017. Dasar pertimbangan pengambilan lokasi penelitian karena Kabupaten Malang merupakan sentra penghasil singkong.

\section{Metode penentuan responden}

Responden yang diamati dalam penelitian ini adalah petani singkong yang ada di Kecamatan Dau, Kecamatan Karangploso, dan Kecamatan Singosari. Menurut Singarimbun dan Effendi (1989), sampel penelitian ini ditentukan dengan metode stratified random sampling dan snowball sampling, dimana metode purposive sampling adalah cara penarikan sampel yang dilakukan dengan memilih subjek berdasarkan kriteria yang telah ditentukan. Pertimbangan yang dimaksud dalam pengambilan sampel dilakukan dengan cara melihat rata-rata luas lahan yang dimiliki oleh petani sebagai sampel pertama. Setelah didapat sampel pertama, selanjutnya menggunakan metode snowball sampling dimana metode ini dilakukan untuk mendapatkan informasi sampel berikutnya dari sampel pertama dan seterusnya sehingga produk sampai ke konsumen.

\section{Metode pengumpulan data}


a. Data Primer yaitu diperoleh melalui wawancara dan observasi langsung serta menyebar kuisioner di tempat penelitian terhadap petani di Kecamatan Dau, Kecamatan Karangploso, dan Kecamatan Singosari yang mendapat pelatihan dan pendampingan teknis budidaya ulat sutera. Sedangkan untuk data berupa kuisioner, kuisioner dibacakan oleh peneliti, sehingga responden akan mudah mengerti dengan pertanyaan yang dibuat oleh peneliti.

b. Data Sekunder yaitu diperoleh dengan teknik dokumentasi yaitu mencatat dan mengumpulkan data dari instansi terkait.

\section{Metode analisis data}

a. Analisis Kelayakan Usaha

(1) Metode Net Present Value (NPV)

Net Present Value merupakan metode yang dipakai untuk menilai usulan proyek investasi yang mempertimbangkan nilai waktu dari uang. Sehingga cash flow yang dipakai adalah cash flow yang di diskontokan atas dasar biaya modal (cost of capital) atau rate of return y perusahaan/interest ratel request rate of return yang diinginkan. Rumusnya sebagai berikut (Bambang Riyanto 2001;127) :

$$
\mathrm{NPV}=\sum_{t-1}^{n} \frac{C F_{1}}{(1+K)^{t}}-\mathrm{I}_{0}
$$

Dimana:

$$
\begin{aligned}
& \mathrm{NPV}=\text { Net Present Value } \\
& \mathrm{CFt} \quad=\text { Arus kas pada tahun ke-t } \\
& \mathrm{K} \quad=\text { Tingkat diskonto } \\
& \mathrm{I} 0 \quad=\text { Investasi awal } \\
& \mathrm{N} \quad=\text { Umur ekonomis }
\end{aligned}
$$

\section{(2) Metode Internal Rate Of Return}

IRR sering diartikan sebagai tingkat pengembalian internal dicari dengan cara trial and error atau interpolasi, dengan kata lain IRR adalah discount rate yang membuat Net Present Value sama dengan nol.
Metode Internal Rate of Return ini menghitung tingkat bunga yang menyamakan nilai sekarang penerimaan-penerimaan kas bersih di masa mendatang. Apabila tingkat bunga ini lebih besar daripada tingkat bunga relevan (tingkat keuntungan yang disyaratkan), maka investasi dikatakan menguntungkan, kalau lebih kecil dikatakan merugikan (Husnan dan Suwarsono Muhammad, 2000).

Nilai Internal Rate of Return tidak diperoleh secara langsung melainkan melalui proses trial and error, yaitu dengan mencari nilai NPV pada tingkat suku bunga tertentu yang dipilih secara acak dan kemudian hasilnya dibandingkan dengan biaya investasi. Setelah itu dilakukan interpolasi dengan menggunakan NPV positif (NPV1) dengan tingkat bunga tertentu (Df1) dan NPV negatif (NPV2) dengan tingkat bunga tertentu lainnya (Df2).Rumus yang digunakan:

$\mathrm{IRR}=\mathrm{DF} 1-\left\{\frac{N P V_{1}}{P V_{2}-P V_{1}}\right\} \times\left(D F_{2}-D F_{1}\right)$

Dimana:

Df1 = Discount factor ke-1;

Df2 = Discount factor ke-2;

NPV1 = NPV jika digunakan discount factor ke-1;

PV1 = Present value of Proceeds pada tingkat bunga yang kecil;

PV2 = Present value of Proceeds pada tingkat bunga yang besar.

Kriteria dalam metode IRR adalah:

1. Apabila IRR > Cost of capital, usulan investasi akan diterima.

2. Apabila IRR < Cost of capital, usulan investasi akan ditolak.

Kelebihan metode IRR adalah :

1. Dalam metode ini pengerjaannya lebih lengkap dan baik. 
2. Tidak mengabaikan aliran kas selama bulan proyek.

Internal rate of return (IRR) adalah tingkat diskonto (discount rate) yang menjadikan sama antara present value dari penerimaan cash dan present value dari nilai atau investasi discount rate/tingkat diskon yang menunjukan net present value atau sama besarnya dengan nol.

\section{b. Analisis SWOT}

Dalam Rangkuti (2006:18), analisis SWOT adalah identifikasi berbagai faktor secara sistematis untuk merumuskan strategi. Analisis ini didasarkan pada logika yang dapat memaksimalkan kekuatan (strength) dan peluang (opportunities), namun secara bersamaan dapat meminimalkan kelemahan (weakness) dan ancaman (treaths).

Analisis SWOT membandingkan faktor eksternal peluang (opportunities) dan ancaman (treats) dengan faktor internal kekuatan (strength) dan kelemahan (weakness), untuk menghasilkan analisis strategi yang tepat. Berikut ini adalah uraiannya:

\section{(1) Strategi SO (Strength-Oppor- tunity)}

Strategi yang berdasarkan jalan pikiran perusahaan, yaitu dengan memanfaatkan seluruh kekuatan untuk memanfaatkan peluang sebesar-besarnya.

(2) Strategi ST (Strength-Treaths)

Strategi dalam menggunakan kekuatan yang dimiliki perusahaan untuk mengatasi ancaman.

(3) Strategi WO (Weakness-Opportunity)

Strategi ini diterapkan berdasarkan pemanfaatan peluang yang ada dengan cara meminimalkan kelemahan yang ada.

(4) Strategi WT (Weakness-Treaths)

Strategi ini didasarkan pada kegiatan yang bersifat defensive (bertahan) dan meminimalkan kelemahan yang ada serta menghindari ancaman.

Menurut Kusumastuti (2015), manfaat dari strategi ini sebaiknya sesuai dengan keadaan perusahaan karena berkaitan dengan kelangsungan sebuah kegiatan usaha. Karena perubahan lingkungan dapat menghambat rencana dan tujuan awal maka perusahaan perlu memantau perubahan dan melakukan analisa untuk mengantisipasi perubahan kondisi dan menyiapkan pengendali sehingga perusahaan dapat mengambil langkah lebih awal untuk menghadapi segala kemungkinan jangka panjang atau sebagai ramalan.

\section{HASIL DAN PEMBAHASAN}

\section{Analisis kelayakan usaha}

a. Biaya Tetap

Biaya tetap adalah besarnya biaya yang dikeluarkan oleh agroindustri dalam proses produksi dan besarnya tidak bergantung dari jumlah produk yang dihasilkan. Biaya tetap yang dikeluarkan meliputi biaya pembelian alat seperti rak, pajak gedung. Biaya tetap dapat dilihat di Tabel 1.

Tabel 1. Biaya tetap dalam satu bulan

\begin{tabular}{clcc}
\hline No. & Keterangan & $\begin{array}{c}\text { Satuan } \\
(\mathbf{R p})\end{array}$ & $\begin{array}{c}\text { Jumlah } \\
(\mathbf{R p})\end{array}$ \\
\hline 1. & Rak & 18.750, & 18.750, \\
2. & Pajak & - & - \\
& gedung/ PBB & $1.000,-$ & $1.000,-$ \\
3. & Kawat/ sekat & 37.500, & 37.500, \\
& rak & - & - \\
Total & $\mathbf{5 7 . 2 5 0 ,}$ & $\mathbf{5 7 . 2 5 0}$, \\
& - & - \\
\hline
\end{tabular}

Sumber : Data Primer Diolah, 2017

Berdasarkan Tabel 1, dapat diketahui bahwa besarnya biaya tetap pada budidaya ulat sutera pemakan daun singkong adalah Rp 57.250,-. Total biaya tetap ini diperoleh dari biaya pembelian rak, pajak gedung atau $\mathrm{PBB}$, dan biaya pembelian 
kawat untuk menyekat rak yang sudah dikonversikan menjadi satu bulan budidaya.

\section{b. Biaya Variabel}

Biaya variabel merupakan biaya yang dikeluarkan oleh agroindustri dalam proses produksi, untuk pembayaran semua input variabel yang digunakan dalam proses produksi. Biaya variabel budidaya ulat sutera terdiri dari biaya bahan baku dan bahan penolong seperti bibit ulat sutera, pakan ulat (daun singkong), kertas cd yang digunakan sebagai alas, tempeh dan bak kemudian biaya transportasi serta gaji tenaga kerja. Berikut adalah rincian biaya variabel dari budidaya ulat sutera.

Berdasarkan Tabel 2, diketahui bahwa biaya variabel dari budidaya ulat sutera dalam satu bulan adalah $\mathrm{Rp}$ 1.630.000,-

Tabel 2. Biaya variabel dalam satu bulan

\begin{tabular}{llcc}
\hline $\mathbf{N}$ & \multicolumn{1}{c}{ Keterangan } & $\begin{array}{c}\text { Harga satuan } \\
\text { o. }\end{array}$ & Biaya (Rp) \\
\hline 1. & Kertas cd 100 lembar & 6.000 & 600.000 \\
2. & Tempeh 10 buah & 5.000 & 50.000 \\
3. & Bak & 30.000 & 30.000 \\
4. & Bibit ulat sutera (per kotak isi 20.000 telur) 5 & 25.000 & 250.000 \\
& kotak & & \\
5. & Pakan ulat (daun singkong) & 100.000 & 100.000 \\
6. & Tenaga kerja & 400.000 & 400.000 \\
7. & Biaya transportasi & 200.000 & 200.000 \\
\hline \multicolumn{2}{r}{ Total Biaya Variabel } & $\mathbf{1 . 6 3 0 . 0 0 0}$ & $\mathbf{1 . 6 3 0 . 0 0 0}$ \\
\hline
\end{tabular}

Sumber : Data Primer diolah 2017

c. Biaya Total

Biaya total adalah penjumlahan dari seluruh biaya tetap dan biaya variabel yang dikeluarkan oleh agroindustri dalam proses produksi. Berikut adalah rincian biaya total dari budidaya ulat sutera dapat dilihat pada Tabel 3 di bawah ini.

Tabel 3. Biaya total per bulan

\begin{tabular}{lc}
\hline \multicolumn{1}{c}{ Keterangan } & Jumlah $(\mathbf{R p )}$ \\
\hline Biaya Tetap & $57.250,-$ \\
Biaya Variabel & $1.630 .000,-$ \\
Total & $1.687 .250,-$ \\
\hline
\end{tabular}

Sumber: Data Primer diolah 2017

Berdasarkan Tabel 3, dapat diketahui bahwa biaya total yang dikeluarkan untuk budidaya ulat sutera dalam satu bulan sebesar Rp 1.687.250,-.

d. Analisis keuntungan

Keuntungan merupakan nilai uang yang diperoleh dari hasil pengurangan penerimaan dengan biaya total yang ada budidaya ulat sutera pemakan daun singkong total yang ada budidaya ulat sutera pemakan daun singkong.

Menurut Soekartawi (1995), penerimaan merupakan perkalian antara produksi yang diperoleh dengan harga jual. Dari budidaya ulat sutera ini produksi total yang diperoleh dalam satu bulan adalah $17,5 \mathrm{~kg}$ x 10 kotak x Rp 20.000,- = Rp 3.500.000,-.

\begin{tabular}{lc}
\multicolumn{2}{c}{ Tabel 4. Penerimaan per bulan } \\
\hline Keterangan & Jumlah $(\mathbf{R p})$ \\
\hline Total Biaya & $1.687 .250,-$ \\
Penerimaan & $3.500 .000,-$ \\
Keuntungan & $1.812 .750,-$ \\
\hline
\end{tabular}

Sumber : Data Primer diolah 2017

Berdasarkan Tabel 4, dapat diketahui bahwa keuntungan yang diperoleh usaha ulat sutera dalam satu bulan budidaya adalah sebesar Rp 1.812.750,-. Berdasarkan hasil analisis 
biaya, penerimaan, dan keuntungan yang telah dilakukan dapat disimpulkan bahwa usaha budidaya ulat sutera pemakan daun singkong menguntungkan sehingga layak untuk dikembangkan.

\section{e. Analisis B/C Rasio}

Merupakan perbandingan antara keuntungan dengan total biaya yang dikeluarkan.

$$
\begin{aligned}
\mathrm{B} / \mathrm{C} \text { rasio } & =\frac{\text { keuntungan yang diperoleh }}{\text { total biaya yang dikeluarkan }} \\
& =\frac{1.812 .750}{1.687 .250}=1,074
\end{aligned}
$$

Dari perhitungan, diketahui bahwa nilai $\mathrm{B} / \mathrm{C}$ rasio sebesar 1,074 yang berarti setiap Rp 1,00 biaya produksi yang dikeluarkan untuk keperluan budidaya ulat sutera dalam kurun waktu 1 bulan akan memberikan keuntungan sebanyak Rp 1,074,-. Karena hasil perhitungan B/C rasio lebih dari satu, maka budidaya ulat sutera pemakan daun singkong ini layak untuk dikembangkan.

Namun jika dibandingkan dengan hasil studi yang dilakukan oleh Dedy
Rustiono dan Trimurti (2015), disimpulkan bahwa nilai $\mathrm{B} / \mathrm{C}$ ratio pada penelitian mereka adalah sebesar 1,84. Memiliki selisih 0,766 lebih besar daripada penelitian yang dilakukan oleh penulis. Hal ini dikarenakan pada penelitian Dedy, dkk melakukan penerapan iptek dalam pengembangan budidayanya.

\section{f. Analisis NPV dan IRR}

Dalam satu bulan biaya yang dikeluarkan untuk budidaya ulat sutera pemakan daun singkong adalah Rp 1.687.250,-, maka dalam satu tahun biaya total yang dikeluarkan adalah sebesar Rp 20.247.000,-. Sedangkan untuk total penerimaan dalam satu tahun adalah $\mathrm{Rp}$ 42.000.000,- serta untuk keuntungan yang diperoleh dalam satu tahun sebesar Rp 21.753.000,-. Dalam perhitungan NPV dan IRR pada penelitian ini menggunakan tingkat inflasi $4 \%$ per tahun dan suku bunga bank BRI $6,4 \%$ pada bulan Juli 2017.

\begin{tabular}{|c|c|c|c|c|c|c|}
\hline No. & $\begin{array}{c}\text { Tahun } \\
\text { ke- }\end{array}$ & Biaya & Penerimaan & Keuntungan & $\begin{array}{c}\text { Dis- } \\
\text { count } \\
\text { rate }\end{array}$ & NPV \\
\hline 1. & 0 & 20.247 .000 & 42.000 .000 & 21.753 .000 & 1 & 21.753 .000 \\
\hline 2. & 1 & 21.056 .880 & 43.680 .000 & 22.623 .120 & 0,94 & 21.279 .064 \\
\hline 3. & 2 & 21.899 .155 & 45.427 .200 & 23.528 .045 & 0,88 & 20.626 .345 \\
\hline 4. & 3 & 22.775 .121 & 47.244 .288 & 24.469 .167 & 0,83 & 19.810 .497 \\
\hline 5. & 4 & 23.686 .126 & 49.134 .060 & 25.447 .933 & 0,78 & 18.776 .961 \\
\hline 6. & 5 & 24.633 .571 & 51.099 .422 & 26.465 .851 & 0,73 & 17.507 .449 \\
\hline \multicolumn{2}{|c|}{ Total } & 134.297 .854 & 278.584 .969 & 144.287 .115 & & 119.753 .316 \\
\hline
\end{tabular}

Tabel 5. Hasil perhitungan evaluasi kelayakan finansial budidaya ulat sutera

Sumber : Data Primer diolah 2017

NPV menunjukkan manfaat bersih yang diterima petani atau investor dalam budidaya ulat sutera pemakan daun singkong di Kabupaten Malang selama 5 tahun menggunakan perkiraan inflasi $4 \%$ per tahun dan pada tingkat suku bunga BRI saat dilakukannya penelitian yaitu $6,4 \%$. Adapun kriteria untuk NPV adalah jika NPV bernilai positif atau bernilai lebih dari 0, maka usaha budidaya tersebut menguntungkan dan layak untuk dikembangkan. Dari tabel diketahui bahwa nilai NPV pada kegiatan budidaya ulat sutera pemakan daun singkong adalah Rp 119.753.316,dan bernilai positif atau lebih dari 0 , 
sehingga dapat disimpulkan bahwa kegiatan budidaya ulat sutera pemakan daun singkong yang terdapat di Kabupaten Malang layak untuk dikembangkan karena mampu memberikan keuntungan cukup besar di masa depan.

Sedangkan untuk analisa IRR dihitung menggunakan rumus sebagai berikut:

$$
\begin{aligned}
\text { IRR } & =i 1+\frac{\text { NPV1 }}{(\text { NPV2-NPV1) }}(i 2-i 1) \\
& =0,94+\frac{21.279 .064}{(20.626 .345-21.279 .064)}(0,88-0,94) \\
& =0,94+(-32,601)(-0,06) \\
& =0,94+\frac{21.279 .064}{-652.719}(-0,06) \\
& =0,94+1,956 \\
& =2,896
\end{aligned}
$$

Suatu usaha dikatakan berhasil jika nilai IRR lebih besar dari tingkat suku bunga yang diisyaratkan. Dari perhitungan nilai IRR diketahui bahwa nilai IRR kegiatan budidaya ulat sutera pemakan daun singkong pada tingkat suku bunga $6,4 \%$ adalah $2,896 \%$. Sehingga dengan menginvestasikan uang ke dalam kegiatan budidaya akan memberikan keuntungan sebesar 2,896\% saja. Dengan demikian, berdasarkan Husnan dan Suwarsono Muhammad (2000), kegiatan budidaya ulat sutera ini belum cukup menguntungkan dan akan lebih menguntungkan jika menginvestasikan uang ke Bank. Kondisi permasalahan seperti ini dapat diatasi dengan intervensi kebijakan Pemerintah dan beberapa perbaikan manajemen dari pihak pengusaha ulat sutera itu sendiri.

\section{Analisis SWOT}

Menurut David (2006), strategi memiliki konsekuensi yang perlu mempertimbangkan faktor-faktor eksternal dan internal dihadapi perusahaan.

Adapun langkah awal untuk menentukan strategi pengembangan budidaya ulat sutera adalah dengan mencari faktor internal dan eksternal yang dimiliki. Pada faktor internal terdapat kekuatan (strength) dan kelemahan (weakness), sedangkan pada faktor eksternal terdapat peluang (opportunity) dan ancaman (threat). 
Tabel 6. Matriks IFE Budidaya Ulat Sutera Pemakan Daun Singkong

\begin{tabular}{|c|c|c|c|c|}
\hline $\begin{array}{c}\text { No } \\
\text {. }\end{array}$ & Faktor Internal & Bobot & $\begin{array}{c}\text { Pering- } \\
\text { kat }\end{array}$ & Skor \\
\hline & Kekuatan (strength) & & & \\
\hline 1 & Modal milik sendiri & 0,04 & 3 & 0,12 \\
\hline 2 & Memiliki pengalaman bisnis & 0,06 & 4 & 0,24 \\
\hline 3 & Pendidikan pemilik tinggi & 0,06 & 3 & 0,18 \\
\hline 4 & $\begin{array}{l}\text { Kualitas SDM akan pengetahuan ulat sutera, budidaya } \\
\text { hingga proses panen tinggi }\end{array}$ & 0,06 & 4 & 0,24 \\
\hline 5 & Lokasi industri strategis & 0,04 & 3 & 0,12 \\
\hline 6 & Berhasil diekspor ke Cina & 0,07 & 4 & 0,28 \\
\hline 7 & Kualitas kokon yang dihasilkan baik & 0,07 & 4 & 0,28 \\
\hline 8 & Ketersediaan bahan baku pakan ulat sutera melimpah & 0,07 & 4 & 0,28 \\
\hline \multirow[t]{3}{*}{9} & $\begin{array}{l}\text { Selalu ada penelitian dan pengembangan lanjutan ter- } \\
\text { hadap ulat sutera }\end{array}$ & 0,06 & 4 & 0,24 \\
\hline & Total kekuatan & $\mathbf{0 , 5 3}$ & & 1,98 \\
\hline & Kelemahan (weakness) & & & \\
\hline 1 & Tidak adanya pelatihan karyawan & 0,05 & 1 & 0,05 \\
\hline 2 & Pengalaman kerja kurang & 0,05 & 1 & 0,05 \\
\hline 3 & Struktur organisasi tidak ada & 0,03 & 1 & 0,03 \\
\hline 4 & $\begin{array}{l}\text { Pelaksanaan sistem manajemen organisasi masih se- } \\
\text { derhana }\end{array}$ & 0,03 & 1 & 0,03 \\
\hline 5 & Karyawan tidak mengetahui visi misi perusahaan & 0,04 & 2 & 0,08 \\
\hline 6 & $\begin{array}{l}\text { Daya tahan produk semakin menurun seiring dengan } \\
\text { waktu }\end{array}$ & 0,05 & 2 & 0,1 \\
\hline 7 & Sistem pembukuan dan adminsitrasi kurang jelas & 0,05 & 2 & 0,1 \\
\hline 8 & Tempat produksi masih sederhana & 0,03 & 1 & 0,03 \\
\hline 9 & $\begin{array}{l}\text { Kurangnya perhatian pada pertumbuhan ulat sutera } \\
\text { akan mengakibatkan hilangnya hasil }\end{array}$ & 0,05 & 1 & 0,05 \\
\hline 10 & $\begin{array}{l}\text { Kualitas alat dan bahan yang dipergunakan masih } \\
\text { terbatas }\end{array}$ & 0,04 & 1 & 0,04 \\
\hline 11 & Penerapan teknologi masih sederhana & 0,05 & 2 & 0,1 \\
\hline & Total kelemahan & 0,47 & & 0,66 \\
\hline & Total kekuatan dan kelemahan & 1,0 & & 2,64 \\
\hline & Selisih skor kekuatan dan kelemahan & & & 1,98 \\
\hline
\end{tabular}

Sumber : Data Primer diolah, 2017

a. Analisis internal

Berdasarkan tabel 6, dapat diketahui bahwa total skor kekuatan adalah sebesar 1,98. Sedangkan total skor kelemahannya adalah 0,66. Dari hal ini dsimpulkan bahwa skor kekuatannya lebih besar daripada skor kelemahannya dengan selisih skor 1,98. Pada sisi kekuatan, yang paling berpengaruh adalah produk berhasil diekspor ke Cina, kualitas kokon yang dihasilkan baik dan ketersediaan bahan baku ulat sutera melimpah. Sedangkan pada sisi kelemahan, faktor yang berpengaruh besar adalah daya tahan produk semakin menurun seiring dengan waktu, sistem pembukuan dan adminisrasi kurang jelas serta penerapan teknologi masih sederhana. 
b. Analisis eksternal

Lingkungan eksternal dalah suatu kekuatan yang berada di luar perusahaan dimana perusahaan tidak mempunyai pengaruh sama sekali terhadapnya sehingga perubahan-perubahan yang terjadi pada lingkungan ini akan mempengaruhi kinerja semua perusahaan dalam industri tersebut (Wahyudi, 1996).

Berdasarkan tabel 7, dapat diketahui bahwa total skor peluang yang dimiliki oleh budidaya ulat sutera pemakan daun singkong adalah sebesar 2,97, sedangkan total skor ancamannya sebesar 0,34. Dapat disimpulkan bahwa total skor peluang memiliki nilai lebih besar daripada skor ancamannya dengan selisih skor 2,63. Pada sisi peluang, faktor yang paling berpengaruh antara lain kegiatan usaha telah memiliki beberapa kerjasama, dapat memberikan lapangan pekerjaan baru, meningkatkan pendapatan masyarakat dan memiliki kemitraan dengan petani singkong sebagai pemasok pakan. Sedangkan pada sisi ancaman, faktor yang berpengaruh yaitu kegiatan usaha tidak memiliki ijin pendirian usaha dan biaya perawatan selama di pelabuhan sampai tujuan mahal. Total skor peluang dan ancaman adalah sebesar 3,31 yang berarti bahwa kegiatan budidaya ulat sutera pemakan daun singkong ini merespon terhadap peluang dan ancaman yang ada.

Tabel. 7. Matriks EFE Budidaya Ulat Sutera Pemakan Daun Singkong

\begin{tabular}{|c|c|c|c|c|}
\hline No. & Faktor Ekstenal & Bobot & Peringkat & Skor \\
\hline & Peluang (opportunity) & & & \\
\hline 1 & Permintaan produk semakin tinggi & 0,06 & 3 & 0,18 \\
\hline 2 & $\begin{array}{l}\text { Bahan baku daun singkong cukup terjangkau dan mu- } \\
\text { dah didapat serta harganya stabil }\end{array}$ & 0,1 & 4 & 0,4 \\
\hline 3 & Pakan daun singkong berkualitas (organik) & 0,1 & 4 & 0,4 \\
\hline 4 & Memberikan lapangan pekerjaan baru & 0,08 & 4 & 0,32 \\
\hline 5 & Meningkatkan pendapatan masyarakat & 0,08 & 4 & 0,32 \\
\hline 6 & Kegiatan usaha telah memiliki beberapa kerjasama & 0,09 & 4 & 0,36 \\
\hline 7 & Memiliki kemitraan dengan petani singkong & 0,08 & 4 & 0,32 \\
\hline 8 & Pemasok bahan baku daun singkong cukup banyak & 0,07 & 4 & 0,28 \\
\hline 9 & Tidak ada pesaing & 0,06 & 3 & 0,18 \\
\hline \multirow[t]{3}{*}{10} & $\begin{array}{l}\text { Sudah ada pengumpul tetap dan mempunyai pangsa } \\
\text { pasar ekspor }\end{array}$ & 0,07 & 3 & 0,21 \\
\hline & Total peluang & $\mathbf{0 , 7 9}$ & & 2,97 \\
\hline & Ancaman (threat) & & & \\
\hline 1 & Kebijakan Pemerintah yang tidak mendukung & 0,04 & 1 & 0,04 \\
\hline 2 & Tidak memiliki surat ijin pendirian usaha & 0,07 & 2 & 0,14 \\
\hline 3 & Dukungan pemerintah daerah belum ada & 0,04 & 1 & 0,04 \\
\hline \multirow[t]{4}{*}{4} & $\begin{array}{l}\text { Biaya perawatan selama di Pelabuhan sampai tujuan } \\
\text { mahal }\end{array}$ & 0,06 & 2 & 0,12 \\
\hline & Total ancaman & $\mathbf{0 , 2 1}$ & & $\mathbf{0 , 3 4}$ \\
\hline & Total peluang dan ancaman & 1,00 & & 3,31 \\
\hline & Selisih skor peluang dan ancaman & & & 2,63 \\
\hline
\end{tabular}

Sumber : Data Primer diolah, 2017

c. Matriks internal eksternal

Untuk dapat menerapkan strategi pengembangan yang tepat, menurut
David (2006) perlu dilakukan analisis terhadap faktor Internal dan Eksternal dari sebuah usaha. Setelah melakukan 
hal tersebut, akan diperoleh Matriks Internal-Eksternal (IE) yang merupakan penggabungan dari analisis IFE dan EFE. Analisis ini bertujuan untuk mengetahui posisi kegiatan usaha. Matriks IE terdiri dari sembilan sel dimana masing-masing sel memiliki strategi yang sesuai untuk diaplikasikan pada kegiatan usaha tersebut. Matriks ini dibuat dengan cara menggambarkan total skor dari matriks IFE yang diletakkan pada sumbu $\mathrm{X}$ dan total skor dari matrisk EFE yang diletakkan pada sumbu Y. Dalam hal ini, nilai X 2,64 adalah dan nilai $Y$ adalah 3,31. Pada gambar merupakan matriks IE dari budidaya ulat sutera pemakan daun singkong.

Berdasarkan gambar 1, dapat diketahui bahwa total skor IFE dan EFE budidaya ulat sutera terletak pada sel II yang merupakan daerah Growth Strategy. Dalam hal ini dikatakan bahwa kegiatan usaha berada pada tahap pertumbuhan. Sedangkan strategi yang dapat dilakukan antara lain mengembangkan usaha, menambah usaha di lokasi lain, mengubah atau meningkatkan kualitas hasil, atau meningkatkan akses ke pasar yang lebih luas.

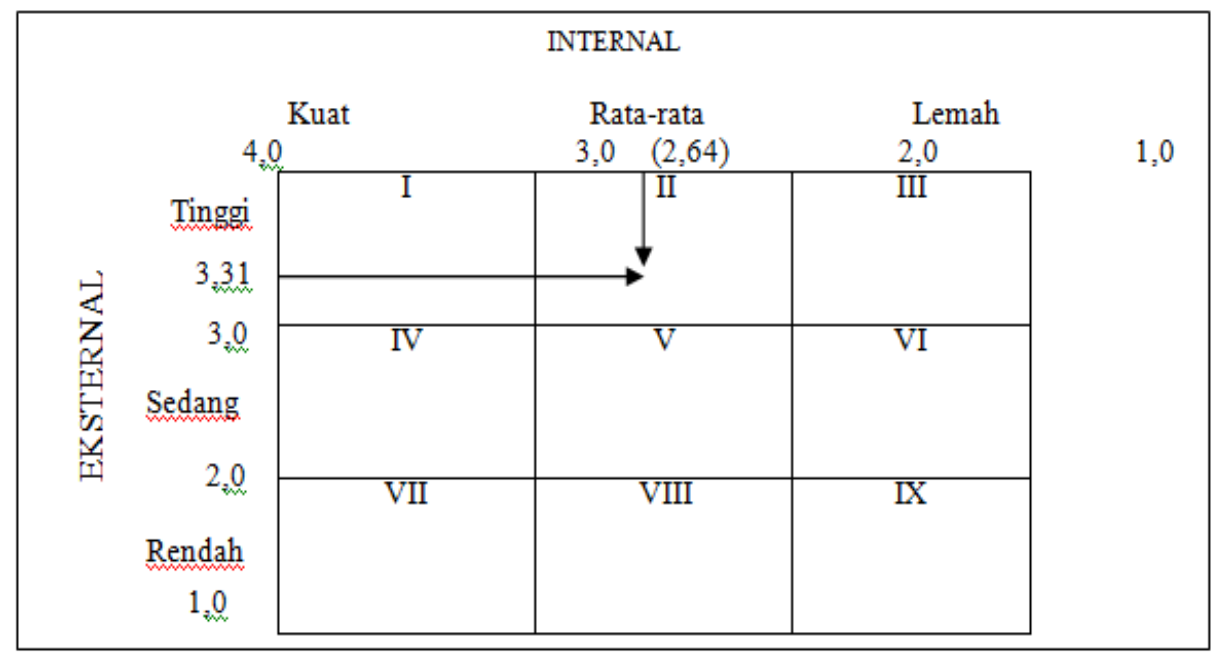

Gambar 1. Matriks Internal-Eksternal

\section{d. Matriks Grand Strategy}

Matriks Grand Strategy merupakan matriks yang digunakan untuk mengetahui posisi kuadran usaha budidaya ulat sutera dari keempat kuadran sehingga dapat diketahui strategi alternatif yang dapat digunakan untuk mengembangkan usaha budidaya.
Matriks ini dibuat dengan cara meletakkan selisih skor pada matriks IFE dan EFE pada sumbu $X \quad(1,98)$ sedangkan selisih untuk sumbu Y-nya $(2,63)$ didapat dari selisih skor pada matriks EFE. Pada gambar merupakan matriks Grand Strategy budidaya ulat sutera pemakan daun singkong. 


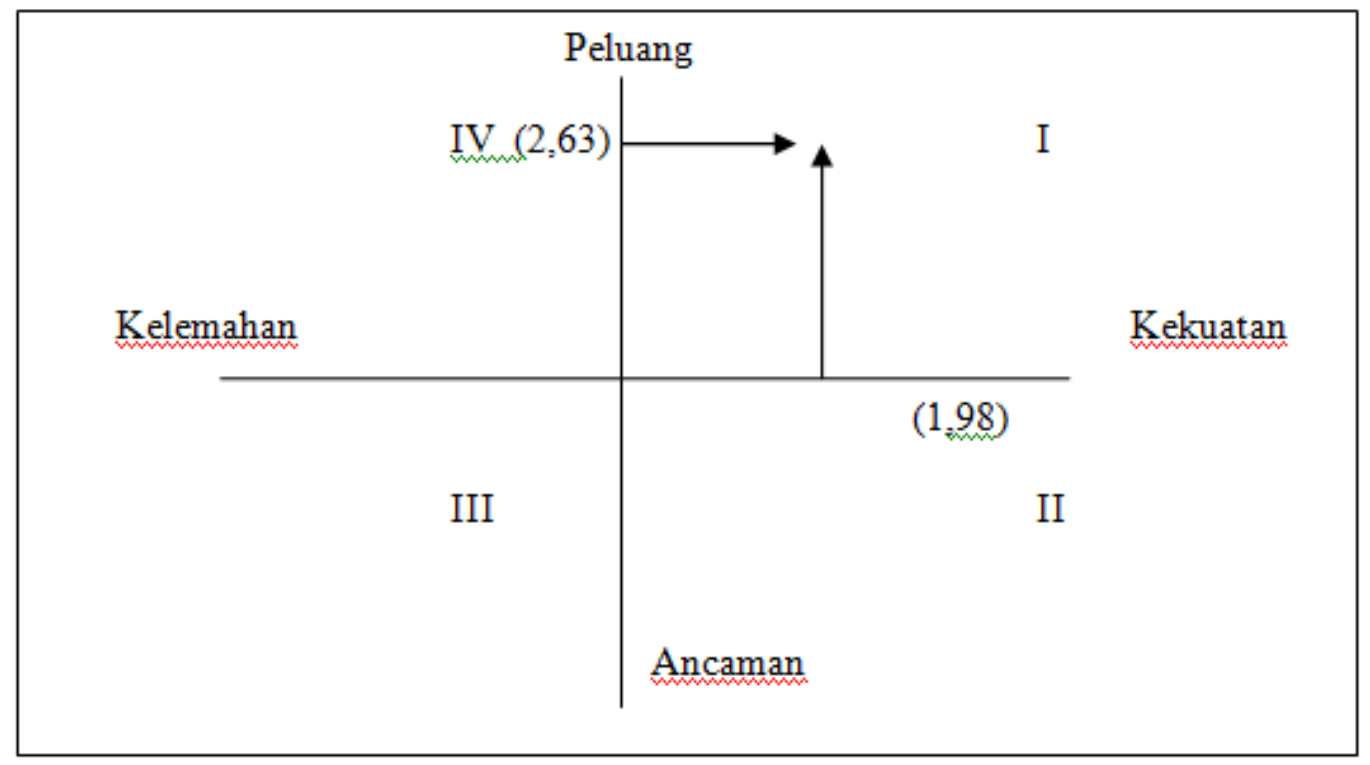

Gambar 2. Matriks Grand Strategy budidaya ulat sutera pemakan daun singkong

Berdasarkan gambar 2, dapat diketahui bahwa posisi budidaya ulat sutera pemakan daun singkong berada pada kuadran I. Menurut David (2001), usaha kegiatan yang berada pada kuadran I memiliki kedudukan strategis yang sangat bagus. Posisi daya saing kuat dan memiliki pertumbuhan pasar yang tinggi. Strategi yang sesuai dengan keadaan ini adalah dengan cara berkonsentrasi pada pengembangan pasar dan kualitas hasil. Strategi pengembangan pasar yang dapat dilakukan pada kegiatan usaha ulat sutera ini adalah dengan meningkatkan kerjasama dengan berbagai pihak agar hasil produksi tetap dapat diekspor ke Cina serta menambah pangsa pasar ke luar negeri. Sedangkan untuk strategi pada produknya, dilakukan dengan cara meningkatkan hasil produksi kokon dan mempertahankan kualitas kokon.

\section{e. Matriks SWOT}

Matriks SWOT menggambarkan dengan jelas bagaimana peluang dan ancaman eksternal terhadap eksistensi kegiatan budidaya ulat sutera serta disesuaikan dengan kekuatan dan kelemahan yang dimilikinya. Pada matriks ini, 4 kolom yang berada di tengah merupakan beberapa alternatif strategi yang dapat dilakukan oleh perusahaan. Tabel berikut merupakan matriks SWOT budidaya ulat sutera pemakan daun singkong di Kabupaten Malang. 
Tabel 8. Matriks SWOT Budidaya Ulat Sutera Pemakan Daun Singkong

\begin{tabular}{|c|c|c|}
\hline & Kekuatan (S) & Kelemahan (W) \\
\hline Faktor Internal & $\begin{array}{l}\text { 1. Modal milik sendiri. (S1) } \\
\text { 2. Memiliki pengalaman } \\
\text { bisnis.(S2) } \\
\text { 3. Pendidikan pemilik } \\
\text { tinggi.(S3) } \\
\text { 4. Kualitas SDM akan } \\
\text { pengetahuan ulat sutera, } \\
\text { budidaya hingga proses } \\
\text { panen tinggi.(S4) } \\
\text { 5. Lokasi industri strate- } \\
\text { gis.(S5) } \\
\text { 6. Berhasil diekspor ke } \\
\text { Cina.(S6) } \\
\text { 7. Kualitas kokon yang } \\
\text { dihasilkan baik.(S7) } \\
\text { 8. Ketersediaan bahan baku } \\
\text { pakan ulat sutera melim- } \\
\text { pah.(S8) } \\
\text { 9. Selalu ada penelitian dan } \\
\text { pengembangan lanjutan } \\
\text { terhadap ulat sutera.(S9) }\end{array}$ & $\begin{array}{l}\text { 1. Tidak adanya pelatihan } \\
\text { karyawan baru.(W1) } \\
\text { 2. Pengalaman kerja ku- } \\
\text { rang.(W2) } \\
\text { 3. Struktur organisasi tidak } \\
\text { ada.(W3) } \\
\text { 4. Pelaksanaan sistem mana- } \\
\text { jemen organisasi masih } \\
\text { sederhana.(W4) } \\
\text { 5. Karyawan tidak menge- } \\
\text { tahui visi misi pe- } \\
\text { rusahaan.(W5) } \\
\text { 6. Daya tahan produk se- } \\
\text { makin menurun seiring } \\
\text { dengan waktu.(W6) } \\
\text { 7. Sistem pembukuan dan } \\
\text { adminsitrasi kurang } \\
\text { jelas.(W7) } \\
\text { 8. Tempat usaha kegiatan } \\
\text { budidaya masih seder- } \\
\text { hana. (W8) } \\
\text { 9. Kurangnya perhatian } \\
\text { pada pertumbuhan ulat } \\
\text { sutera akan mengakibat- } \\
\text { kan hilangnya hasil. (W9) } \\
\text { 10. Kualitas alat dan bahan } \\
\text { yang dipergunakan } \\
\text { terbatas.(W10) } \\
\text { 11.Penerapan teknologi } \\
\text { masih sederhana. (W11) }\end{array}$ \\
\hline $\begin{array}{l}\text { Peluang (O) } \\
\text { 1. Permintaan produk } \\
\text { semakin tinggi.(O1) } \\
\text { 2. Bahan baku daun } \\
\text { singkong cukup ter- } \\
\text { jangkau dan mudah } \\
\text { didapat serta har- } \\
\text { ganya stabil.(O2) } \\
\text { 3. Pakan daun sing- } \\
\text { kong berkualitas (or- } \\
\text { ganik).(O3) } \\
\text { 4. Memberikan lapan- } \\
\text { gan pekerjaan } \\
\text { baru.(O4) }\end{array}$ & \begin{tabular}{|l}
\multicolumn{1}{c}{ Strategi SO } \\
1. Menjaga kualitas SDM \\
(S4,S6,S7,O1) \\
2. Mencari partner untuk \\
mengembangkan bisnis \\
budidaya ulat sutera \\
(S6,O4,O5,O9) \\
3. Meningkatkan kapasitas \\
produksi (S2, S8, S9,O1, \\
O7, O8,O10) \\
4. Memperluas kegiatan \\
usaha (S5,S9,O4,O5) \\
5. Mempertahankan kualitas \\
kokon (S7, S9,O1)
\end{tabular} & $\begin{array}{l}\text { 1. Mengadakan bimbingan } \\
\text { dan pelatihan kepada kar- } \\
\text { yawan.(W1,W2,W9,O1) } \\
\text { 2.Perbaikan sistem mana- } \\
\text { jemen yang lebih kondu- } \\
\text { sif.(W4,W5,W6,W7,W10, } \\
\text { O1,O9) } \\
\text { 3. Mengembangkan dan } \\
\text { memperluas usaha } \\
\text { kegiatan budi- } \\
\text { daya.(W8,O4,O6) } \\
\text { 4. Mengoptimalkan hub- } \\
\text { ungan kerjasama dengan }\end{array}$ \\
\hline
\end{tabular}




\begin{tabular}{|c|c|c|}
\hline $\begin{array}{l}\text { 5. Meningkatkan pen- } \\
\text { dapatan masyara- } \\
\text { kat.(O5) } \\
\text { 6. Kegiatan usaha telah } \\
\text { memiliki beberapa } \\
\text { kerjasama. (O6) } \\
\text { 7. Memiliki kemitraan } \\
\text { dengan petani sing- } \\
\text { kong. (O7) } \\
\text { 8. Pemasok bahan baku } \\
\text { daun singkong } \\
\text { cukup banyak. (O8) } \\
\text { 9. Tidak ada pesaing. } \\
\text { (O9) } \\
\text { 10. Sudah ada pen- } \\
\text { gumpul tetap dan } \\
\text { mempunyai pangsa } \\
\text { pasar ekspor. (O10) }\end{array}$ & $\begin{array}{l}\text { 6. Memperluas wilayah } \\
\text { pemasaran }(\mathrm{S} 2, \mathrm{~S} 6, \mathrm{O} 6) \\
\text { 7. Menjaga hubungan baik } \\
\text { dengan pemasok dan } \\
\text { pengepul untuk ekspor } \\
(\mathrm{S} 8, \mathrm{O} 2, \mathrm{O} 3)\end{array}$ & $\begin{array}{l}\text { berbagai pihak } \\
\text { (W6,W8,W11,O1,O2,O3, } \\
\text { O6,O7,O8,O9,O10) } \\
\text { 5. Mengembangkan mutu } \\
\text { alat dan bahan serta pen- } \\
\text { erapan } \\
\text { teknologi.(W10,O1,O10) } \\
\text { 6. Mengembangkan penyim- } \\
\text { panan } \\
\text { produk.(W6,W9,O1,O10) }\end{array}$ \\
\hline $\begin{array}{l}\text { Ancaman (T) } \\
\text { 1. Kebijakan } \\
\text { Pemerintah yang } \\
\text { tidak men- } \\
\text { dukung.(T1) } \\
\text { 2. Tidak memiliki surat } \\
\text { ijin pendirian } \\
\text { usaha.(T2) } \\
\text { 3. Dukungan } \\
\text { Pemerintah Daerah } \\
\text { belum ada. (T3) } \\
\text { 4. Biaya perawatan se- } \\
\text { lama di Pelabuhan } \\
\text { sampai tujuan mahal. } \\
\text { (T4) }\end{array}$ & \begin{tabular}{l}
\multicolumn{1}{c}{ Strategi ST } \\
1. Mengurus surat perijinan \\
usaha $(\mathrm{S} 2, \mathrm{~S} 6, \mathrm{~S} 9, \mathrm{~T} 1, \mathrm{~T} 2)$ \\
2. Menerapkan sistem ma- \\
najemen yang baik \\
(S2,S3,S5,S9,S7,T3,T4)
\end{tabular} & $\begin{array}{l}\quad \text { Strategi WT } \\
\text { 1. Melakukan perbaikan } \\
\text { tempat } \\
\text { produksi.(W6,W8,W10, } \\
\text { W11,T2) } \\
\text { 2. Melakukan perbaikan } \\
\text { sistem manajemen keu- } \\
\text { angan, organisasi dan } \\
\text { produksi.(W3,W4,W5,W } \\
\text { 7,W8,W9,W10,W11,T1, } \\
\text { T2,T3) } \\
\text { 3. Melengkapi sarana untuk } \\
\text { penyimpanan hasil ko- } \\
\text { kon.(W6,W9,T4) }\end{array}$ \\
\hline
\end{tabular}

Sumber : Data Primer diolah 2017

Berdasarkan analisis SWOT pada Tabel 8 di atas, dapat diketahui bahwa alternatif strategi yang dapat diberikan untuk kegiatan usaha budidaya ulat sutera pemakan daun singkong ini adalah sebagai berikut:

a. Strategi S-O
1) Menjaga (S4,S6,S7,O1)
SDM

2) Mencari partner untuk mengembangkan bisnis budidaya ulat sutera (S6,O4,05,09)

3) Meningkatkan kapasitas produksi (S2, S8, S9,O1, O7, O8,O10)

4) Memperluas kegiatan usaha (S5,S9,04,O5)

5) Mempertahankan kualitas kokon (S7, S9,O1) 
6) Memperluas wilayah pemasaran (S2,S6,06)

7) Menjaga hubungan baik dengan pemasok dan pengepul untuk ekspor $(\mathrm{S} 8, \mathrm{O} 2, \mathrm{O} 3)$

b. Strategi S-T

1) Mengurus surat perijinan usaha (S2,S6,S9,T1,T2)

2) Menerapkan sistem manajemen yang baik (S2,S3,S5,S9,S7,T3,T4)

c. Strategi W-O

1) Mengadakan bimbingan dan pelatihan kepada karyawan. (W1,W2,W9,O1)

2) Perbaikan sistem manajemen yang lebih kondusif. (W4,W5,W6,W7,W10,O1,O9)

3) Mengembangkan dan memperluas usaha kegiatan budidaya. (W8,04,O6)

4) Mengoptimalkan hubungan kerjasama dengan berbagai pihak.

(W6,W8,W11,O1,O2,O3,06,O7 ,O8,09,010)

5) Mengembangkan mutu alat dan bahan serta penerapan teknologi. (W10,O1,O10)

6) Mengembangkan penyimpanan produk. (W6,W9, O1,O10)

d. Strategi W-T

1) Melakukan perbaikan tempat produksi (W6,W8,W10,W11,T2)

2) Melakukan perbaikan sistem manajemen keuangan, organisasi dan produksi.

(W3,W4,W5,W7,W8,W9,W10, $\mathrm{W} 11, \mathrm{~T} 1, \mathrm{~T} 2, \mathrm{~T} 3)$

3) Melengkapi sarana untuk penyimpanan hasil kokon. (W6,W9,T4).

Analisis yang dilakukan ini sudah berdasarkan Rangkuti (2006), yaitu dengan menerapkan logika yang dapat memaksimalkan kekuatan dan peluang, namun secara bersamaan dapat meminimalkan kelemahan dan ancaman.

\section{KESIMPULAN}

Berdasarkan hasil penelitian yang telah dilakukan, maka dapat disimpulkan beberapa hal sebagai berikut:

1. Analisis agribisnis dari ulat sutera pemakan daun singkong di Kabupaten Malang menguntungkan. Hasil perhitungan dari biaya total dalam kurun waktu satu tahun adalah sebesar Rp 20.247.000,-. Sedangkan total penerimaannya adalah sebesar Rp 42.000.000,-; dan keuntungan yang diperoleh adalah sebesar Rp 21.753.000,-. Nilai NPV nya 119.753.316,- pada tahun kelima dan IRR bernilai $2,896 \%$.

2. Strategi pengembangan yang diperoleh dari matriks SWOT berdasarkan atas analisis internal eksternal SO, S-T, W-O dan W-T S-O, S-T, W$\mathrm{O}$ dan W-T. Analisis strategi S-O yang dilakukan: menjaga kualitas SDM, mencari partner untuk mengembangkan bisnis budidaya ulat sutera, meningkatkan kapasitas produksi, memperluas kegiatan usaha, mempertahankan kualitas kokon, memperluas wilayah pemasaran, menjaga hubungan baik dengan pemasok dan pengepul untuk ekspor. Analisis strategi S-T yang dilakukan: mengurus surat perijinan usaha, menerapkan system manajemen yang baik. Analisis strategi W-O yang dilakukan: mengadakan bimbingan dan pelatihan kepada karyawan, perbaikan sistem manajemen yang lebih kondusif, mengembangkan dan memperluas usaha kegiatan budidaya, mengoptimalkan hubungan kerjasama dengan berbagai pihak, mengembangkan mutu alat dan bahan 
serta penerapan teknologi dan mengembangkan penyimpanan produk. Sedangkan analisis strategi W-T yang dilakukan: melakukan perbaikan tempat produksi, melakukan perbaikan sistem manajemen keuangan, organisasi dan produksi serta melengkapi sarana untuk penyimpanan hasil kokon.

\section{DAFTAR PUSTAKA}

Bambang, Riyanto. (2001). Dasar-Dasar Pembelanjaan Edisi Keempat, Cetakan Ketujuh Perusahaan. Yogyakarta: BPFE Yogyakarta.

David, F. R. (2001). Strategic Management: Concepts and Cases. 8th ed. New Jersey: Prentice Hall, Inc.

David, F. R. (2006). Manajemen Strategi, Edisi Kesepuluh. Jakarta: PT. Intan Sejati Klaten.

Departemen Kehutanan RI, 1999. Pelepasan Bibit Ulat Sutra. (Online)www.dephut.go.id/inde x.php/news/details/3097. DIakses tanggal 10 Mei 2017

Husnan, Suad and Suwarsono Muhammad. (2000). Studi Kelayakan Proyek. Edisi Keempat. Yogyakarta: Penerbit UPP AMP YKPN.

Kusumastuti, Anie Eka. (2015), Analisis SWOT pengadaan bahan baku pakan konsentrat sapi perah di Koperasi SAE Pujon Kabupaten Malang, Jurnal Ilmu-Ilmu Peternakan, 25 (3), 15-24.doi : jiip.ub.ac.id/index.php/jiip/articl e/view/219/319.
Rangkuti, Freddy. ((2009). Strategi Promosi yang Kreatif dan Analisis Kasus Integrated Marketing Communication. Jakarta: PT. Gramedia Pustaka Utama.

Rustiono, Dedy. (2008), Pemberdayaan Petani Oleh Penyuluh Untuk Pengembangan Usaha Tani Padi Organik di Desa Pondok Kecamatan Nguter Kabupaten Sukoharjo Jawa Tengah, Tesis, Program pasca Sarjana Universitas Sebelas Maret Surakarta.

Soekartawi. (1995). Agroindustri Dalam Perspektif Sosial Ekonomi. Jakarta: Raja Grafindo Persada.

Singarimbun, M. dan Effendi, S., ed (1989) Metode Penelitian Survai. Jakarta: Pustaka LP3ES Indonesia.

Wahyudi, Agustinus S. (1996). Manajemen Strategik "Pengantar Proses Berpikir Strategik". Jakarta: Binapura Aksara. 